\title{
Mycorrhizal fungi as mediators of defence against insect pests in agricultural systems
}

\author{
Rachel L. Vannette and Mark D. Hunter \\ Department of Ecology and Evolutionary Biology, University of Michigan, 2086 Kraus Natural Sciences Building, 830 North University Avenue, Ann \\ Arbor, MI 48109-1048, U.S.A.
}

\begin{abstract}
Below-ground organisms influence above-ground interactions in both natural and agricultural ecosystems. Among the most important below-ground organisms are mycorrhizal fungi, comprising ubiquitous and ancient plant mutualists that have significant effects on plant growth and fitness mediated by resource exchange with plants. In the present study, we focus on the effects of arbuscular mycorrhizal fungi (AMF) on crop defence against insect pests.

2 AMF alter the availability of resources used by crop plants to manufacture defences against pests and to compensate for pest damage. However, AMF also provide plants with nutrients that are known to increase insect performance. Through potentially opposing effects on plant nutritional quality and defence, mycorrhizal fungi can positively or negatively affect pest performance.

3 Additionally, AMF may directly affect gene expression and plant defence signalling pathways involved in the construction and induction of plant defences, and these effects are apparently independent of those caused by nutrient availability. In this way, AMF may still influence plant defences in the fertilized and highly managed systems typical of agribusiness.

4 Because AMF can affect plant tolerance to pest damage, they may have a significant impact on the shape of damage-yield relationships in crops. Potential mechanisms for this effect are suggested.

5 We highlight the need for continuing research on the effects of AMF identity and the abundance on crop defences and tolerance to pest attack. Much work is needed on the potential effects of mycorrhizal colonization on plant signalling and the induction of direct and indirect defences that may protect against pest damage.
\end{abstract}

Keywords Agroecosystem, arbuscular mycorrhizal fungi, defence syndrome, integrated pest management, nutrient availability, organic agriculture, resistance, tolerance.

\section{Introduction}

Most plants, including food and fibre crops, use direct and indirect defences to decrease herbivore performance and reduce their subsequent rates of population growth (Speight et al., 2008). Although it has been known for decades that the expression of plant defence varies with resource availability in soils (Bryant et al., 1983; Herms \& Mattson,

Correspondence: Rachel L. Vannette. Tel: +1 (734) 936 2173; fax: +1 (734) 763 0544; e-mail: raleva@umich.edu
1992), more recent studies have highlighted the importance of soil biota in mediating plant resistance and tolerance to insect attack (Wardle et al., 2004; Bezemer \& van Dam, 2005). The soil biota include a diverse array of fungi, bacteria, protists and metazoa that act as decomposers, pathogens, herbivores, mutualists and predators below ground (Coleman et al., 2004). Direct and indirect interactions between soil biota and plants influence all aspects of plant ecology, from molecular to landscape scales (Hooper et al., 2000). 
Some interactions between land plants and soil biota are ancient. Both fossil and molecular evidence suggest that arbuscular mycorrhizal fungi (AMF) in the phylum Glomeromycota have been interacting with land plants for over 400 million years (Redecker et al., 2000) and have played a key role in the diversification of plants (Wang \& Qiu, 2006). Today, the large majority of land plants form associations with mycorrhizal fungi, exchanging hexose sugars gained from photosynthesis for soil resources, commonly phosphorus, nitrogen and/or water (Smith \& Read, 2008). In other words, key resources that are commonly recognized to influence plant resistance and tolerance to insect attack are in part provided to plants by mycorrhizal fungi. We might therefore expect $a$ priori that variation in the abundance, diversity, identity and colonization level of mycorrhizal fungi should influence plant defence against herbivore attack.

That being said, it is no simple matter to predict whether varying levels of association with mycorrhizal fungi should increase or decrease levels of plant defence. For example, the allocation of carbon to fungal associates may be at the expense of the allocation to carbon-rich defensive compounds. By contrast, if allocation of carbon to mycorrhizal fungi increases the rate of phosphorus and nitrogen uptake by plants, enzymatic costs of defence production (Gershenzon, 1994) may be reduced. Moreover, higher levels of resource uptake by mycorrhizal plants may facilitate re-growth after damage, namely tolerance (Van der Meijden et al., 1988), as a dominant defensive strategy (Bennett et al., 2006). As an additional complication, the relative costs and benefits of symbioses can be fluid, such that mycorrhizal associations can range from mutualism to parasitism (Johnson et al., 1997). Under such circumstances, optimal levels of investment in defence traits may vary among the participants in the symbiosis.

We review what is known about the effects of mycorrhizal fungi on plant resistance and tolerance to herbivore attack, with particular reference to crops in agricultural systems. We explore whether generalizations can be made from the available data and suggest some directions for future research. Because $80 \%$ of land plant species associate with AMF in the Phylum Glomeromycota, including most of the nonwoody species typical of agricultural production, (Smith \& Read, 2008), we focus our attention on $\mathrm{AMF}$-crop-insect interactions.

\section{Mycorrhizae in agricultural systems}

Despite often intense management by humans, crop plants are almost always colonized by AMF in agricultural ecosystems. However, the composition of AMF communities and the abundance of fungal inoculum vary substantially among sites and, in general, mycorrhizal colonization of crop plants is limited by the availability of fungal inoculum in agricultural soils (Lekberg \& Koide, 2005). Agricultural practices such as fertilization and tillage tend to decrease AMF abundance and alter community composition (Treseder, 2004; EgertonWarburton et al., 2007; Alguacil et al., 2008; Piotrowski \& Rillig, 2008). Similarly, crop rotation can disrupt the development of long-term crop-AMF associations, and the order of crop rotation affects AMF community composition (Lekberg et al., 2008).
Is this relevant to crop performance and defence against insect herbivores? Traditionally, mycorrhizal fungi have not received much attention with respect to high-input agriculture because they are considered to provide little benefit to heavily-fertilized and irrigated crops in conventional agricultural systems. In heavily-fertilized systems, mycorrhizal fungi are thought to be extraneous and may even become parasitic by exacting a carbon cost to crop plants at the same time as providing negligible benefit (Johnson, 1993). However, this view overlooks two key points regarding AMF in agricultural systems. First, we are just beginning to recognize the additional effects of AMF colonization on plant physiology and gene expression. There is accumulating evidence that fungal infection elicits specific molecular mechanisms within plants, irrespective of nutrient benefits, that can act to augment plant defences and prime the plant against attack by insect herbivores (Hause et al., 2002; Conrath et al., 2006; Hause et al., 2007; Van Wees et al., 2008). Second, the nutrients and water provided by AMF can substantially benefit crop plant performance in low-input or organic agricultural systems (Lekberg \& Koide, 2005; Piotrowski \& Rillig, 2008). In other words, AMF may have a significant role to play in the defences of crop plants across a wide variety of management regimes and intensities. We devote the rest of this review to summarizing the documented changes in plant defence, physiology and allocation patterns elicited by mycorrhizal fungi, and the subsequent effects on insect pest performance and population dynamics.

\section{Mechanisms of mycorrhizal effects on plant defence and insect responses}

If $\mathrm{AMF}$ have a significant impact on crop defences, they must do so through their impacts upon plant traits that confer resistance or tolerance to insect attack. Plant traits that act to deter herbivory or decrease assimilation by insect herbivores can be expressed constitutively or can be induced by herbivory (Karban \& Baldwin, 1997). Traditionally, constitutive and induced defence traits are categorized as direct (physical, chemical, nutritional) or indirect (attraction of herbivore enemies) and the combined suite of defence traits that a plant species exhibits can be characterized as its 'defence syndrome' (Agrawal \& Fishbein, 2006). Many agricultural plants produce both direct and indirect defences against herbivory. For example, cotton, tobacco and maize plants produce the direct chemical defences gossypol, nicotine and 2,4-dihydroxy-7-methoxy-1,4benzoxazin-3-one, respectively (Speight et al., 2008), at the same time as also releasing volatile organic compounds upon herbivore attack that attract parasitoids (De Moraes et al., 1998). Additionally, crop plants exhibit varying levels of tolerance to herbivory (Rosenthal \& Kotanen, 1994). Tolerance is a defensive strategy in which re-growth after attack is selected over resistance (Van der Meijden et al., 1988) and varies, for example, among genotypes of Brassica rapa (Stowe, 1998). Colonization by mycorrhizal fungi can affect direct and indirect defences, as well as plant tolerance to herbivory, by changes in plant nutrition, or by altering plant gene expression independently of plant nutrition. We provide examples of these below, although there is a lack of studies in which the mechanism 
behind the mycorrhizal effect on plant defence is firmly established.

\section{Effects of AMF on crop defence based on plant nutrition}

The exchange of carbon and nutrients between plant-fungal partners (Smith \& Read, 2008) suggests that AMF should increase the phosphorus (and sometimes nitrogen) content of plant tissue at the expense of photosynthate. Herbivores generally favour host plants with high tissue concentrations of nitrogen and phosphorus (Elser et al., 2000; Denno \& Fagan, 2003; Woods et al., 2004) and we might predict that colonization of plants by AMF should be positively associated with herbivore preference and/or performance.

Indeed, this simplistic model has been supported with various crop plant species and their insect pests. For example, mycorrhizal colonization positively affects the growth of soybean Glycine max and the performance of herbivore Epilachna varivestis (Mexican bean beetle) under phosphorus stress (Borowicz, 1997). By contrast, AMF have no influence on beetle damage when plants are grown under adequate phosphorus nutrition (Borowicz, 1997). Similarly, lepidopteran larvae exhibit higher survivorship and growth on mycorrhizal Lotus corniculatus (a pasture, hay and silage crop) than on nonmycorrhizal controls under low phosphorus availability (Goverde et al., 2000). Both of these examples support the idea that AMF can release insect herbivores from phosphorus limitation and increase the subsequent damage inflicted upon their hosts. However, both of these crop species are highly mycorrhizal-dependent; mycorrhizal plants are 20-40fold larger than nonmycorrhizal plants and contain three-fold more phosphorus in their tissues. In such cases, insects will probably perform better on mycorrhizal plants but the plants will also be much more tolerant of the herbivore damage.

For plants with a lower mycorrhizal dependence (Janos, 2007) that can acquire adequate nutrients without the assistance of mycorrhizal fungi, such as many crop cultivars (Tawaraya, 2003), the balance of nutrient intake and carbon cost of AMF may determine resistance and tolerance to herbivores. Nutrientlimited plants may be more able to defend themselves against herbivory when provided with additional nitrogen or phosphorus with which to construct the enzymes and physical structures required for defence (Gershenzon, 1994; Hamilton et al ., 2001). Under this scenario, herbivore preference and performance should be negatively associated with the degree of plant colonization by AMF. Consistent with this prediction, we do observe an increase in the levels of putatively defensive secondary compounds in a number of plant species when inoculated with mycorrhizal fungi. Higher foliar nicotine concentrations are found in mycorrhizal Nicotiana tabacum than in nonmycorrhizal plants (Subhashini \& Krishnamurty, 1995). In addition, the leguminous tree Castanospermum australe produces higher foliar alkaloid concentrations than control plants when inoculated with mycorrhizal fungi (AbuZeyad et al., 1999). Interestingly, mycorrhizal Castanospermum seedlings still produce higher alkaloid concentrations than nonmycorrhizal seedlings that are fertilized with phosphorus, the dominant nutrient provided by AMF. The authors suggest that mycorrhizal colonization may stimulate root nodulation, increasing plant supply of both nitrogen and phosphorus (Crush, 1974). Mycorrhizal colonization also increases the carbonbased defensive compounds acubain and catapol in the weed species Plantago lanceolata, with subsequent decreases in consumption and growth by the generalist chewer Arctia caja (Gange \& West, 1994). This effect may be the result of either stimulation of plant photosynthetic rates (Miller et al., 2002) or an increase in the availability of nutrients that limit the construction of iridoid glycosides. However, high levels of fungal colonization may extract a significant carbon cost and outweigh the nutritional benefit gained by plants, especially in nutrientrich environments (Johnson, 1993). We suggest that positive effects of AMF on plant defence, as a result of increases in the nutritional status of plants, will be stronger in traditional lowinput or organic agricultural systems than in modern high-input agricultural systems.

\section{Effects of AMF on crop defence based on signalling and priming}

Recall that the principle currency for AMF in the mycorrhizal mutualism is hexose sugar gained by the plant through photosynthesis. We might therefore expect that natural selection will favour AMF that participate in the defence of photosynthetic tissues, irrespective of the nutritional status of the plant. Such direct effects of AMF on plant defence might continue to operate in crops that are grown in the heavily-fertilized environments typical of modern agriculture. Interestingly, a recent review of plant hormones affected by mycorrhizal colonization posits a key role for jasmonates in the establishment of AMF colonization and the subsequent effects on plant physiology (Hause et al., 2007). Mature mycorrhizal colonization increases jasmonic acid (JA) concentrations local to infection sites over nonmycorrhizal controls in a variety of crop plants (Hause et al., 2002; Meixner et al., 2005). From transcriptome studies, we know that increases in JA levels are followed by the activation of genes involved in plant defence responses (Hunter, 2000), such as those coding for proteinase inhibitors, enzymes of phytoalexin synthesis, vegetative storage proteins, thionins and defensins (Devoto \& Turner, 2005; Lorenzo \& Solano, 2005). Through its effect on JA levels, mycorrhizal colonization 'primes' systemic plant defences to respond to biotic or abiotic stressors (Conrath et al., 2006). Priming increases the speed and magnitude of induced responses to biotic or abiotic stressors, but elicits little systematic change in current defence levels. The activity of mycorrhizal fungi, as well as other beneficial microbes in triggering JA-induced responses results in induced systemic resistance (ISR) (van Loon et al., 1998). Triggering ISR responses is an effective means of protection against herbivory and is currently used in agricultural systems; plants treated with elicitors of ISR or systemic acquired resistance display increased resistance to pests and reductions in damage greater or equal to pesticide treatment (Vallad \& Goodman, 2004). 
Although transcriptome analyses reveal changes in plant physiology and molecular mechanisms of defence with mycorrhizal colonization (Liu et al., 2007; Feddermann et al., 2008), relatively few studies have examined how mycorrhizal fungi alter induced defences and the corresponding effects on herbivore performance. The available evidence is largely circumstantial. For example, many studies find that generalist chewers, those most likely to elicit JA-mediated induced defences, tend to perform more poorly on mycorrhizal crop plants than on controls (Gange et al., 2002).

In one intriguing example of this phenomenon, Gange (2001) grew strawberries, Fragaria $\times$ ananassa, with no AMF, with Glomus mosseae, with Glomus fasciculatum, or with both AMF species together. Plants were then exposed to the black vine weevil Otiorhynchus sulcatus, which have polyphagous root-feeding larvae. Both weight gain and the survival of $O$. sulcatus larvae were lower on plants colonized by either AMF species alone but colonization by both fungal species resulted in larval biomass and survival that was not significantly different from controls (Gange, 2001). Neither constitutive, nor induced defences were quantified, so the mechanisms underlying changes in herbivore performance were not elucidated.

If $\mathrm{AMF}$ indeed affect the induction response of plants, we might expect aphid herbivores to respond differently to mycorrhizal plants than do chewers. Attack by phloemfeeding insects sometimes fails to trigger JA-induced responses in plants, instead inducing salicylic acid responses (Hunter, 2000; Heidel \& Baldwin, 2004). Possibly because they may circumvent JA-induction of plant defences, some studies have found that aphids and other sucking or piercing insects perform better on mycorrhizal than on nonmycorrhizal plants. For example, the aphid Myzus persicae grows faster and produces more embryos on the mycorrhizal weed $P$. lanceolata than on plants treated with fungicide (Gange \& West, 1994). If aphids do indeed fail to trigger JA defences in mycorrhizal plants, they may simply benefit from the higher nutritional status of plants associated with AMF (see above).

As noted earlier, a majority of studies finds that colonization of crops by AMF decreases the performance of generalist chewing insects and increases that of phloem-feeding insects, consistent with the hypothesis that JA-induced resistance increases in mycorrhizal plants. However, not all insects with sucking or piercing mouthparts can avoid inducing the JA defence pathway in plants (Hunter, 2000) and it should not be unexpected that some of them perform less well on mycorrhizal plants. For example, performance of the mirid Tupiocoris notatus declines on tobacco plants that are colonized by AMF (Wooley \& Paine, 2007), although the precise mechanism underlying this response is unclear.

AMF may also increase or decrease the production of indirect defences by crops. For example, inoculation with AMF significantly reduces the number of extrafloral nectaries (EFNs) produced by Fava beans (Vicia faba) compared with nonmycorrhizal controls (Laird \& Addicott, 2007). A reduction in EFNs may reduce the attraction of predatory ants to the plants. Whether the reduction in EFNs on Fava beans, and presumably in overall nectar output by plants, represent a tradeoff in carbon allocation between AMF and nectaries remains unknown. In addition to their influence on EFNs, AMF may also affect the quantity and quality of volatile organic compounds (VOCs) emitted by host plants (Gange et al., 2003; Rapparini et al., 2008), a cue that can increase parasitoid attack on herbivores (Hunter, 2002, 2003). For example, Diglyphus isaea, a parasitoid of the leaf-miner Chromatomyia syngenesiae, is differentially attracted to Leucanthemum vulgare plants grown with different species of AMF (Gange et al., 2003). Although the mechanism underlying this effect is unknown, it is suggested that AMF-induced variation in plant size or volatile emission may have affected parasitoid behaviour. By contrast, mycorrhizal tomato plants (Solanum lycopersicum) are more attractive to the parasitoid Aphidius ervi than are nonmycorrhizal plants in wind tunnel bioassays (Guerrieri et al., 2004). Once again, the present study did not measure volatile emission directly or control for AMF-induced variation in plant size. We have identified only a single study that examined the effects of AMF colonization on the quantity and quality of VOC emission by a crop plant. Rapparini et al. (2008) demonstrated that mycorrhizal Artemisia annua (sweet wormwood, a salad herb) releases a slightly different blend of VOCs than do nonmycorrhizal, phosphorous-fertilized plants per unit plant tissue. Taken together, these studies strongly suggest that AMF can mediate changes in the deployment of indirect defences by plants.

\section{Effects of AMF on plant tolerance to herbivory}

Theory predicts that AMF should influence plant tolerance to herbivore damage (Bennett et al., 2006), and a few studies have examined this interaction, although with mixed results. In one experiment, a mixture of native prairie plants were grown in a fully factorial experiment, with a mixture of AMF species or without AMF, and subjected to grasshopper herbivory or no herbivory (Kula et al., 2005). On average, both mycorrhizal and nonmycorrhizal plants received similar amounts of herbivory, suggesting that they exhibited equal levels of resistance. The biomass of the herbivory-treated mycorrhizal prairie plant community, however, was not significantly different from the mycorrhizal control, whereas the nonmycorrhizal plant community that received herbivory had, on average, significantly less biomass than the nonmycorrhizal control. Within the plant community, two of the warm season grasses that sustained the least amount of herbivore damage, Andropogon gerardii and Sorghastrum nutans, exhibited overcompensation to herbivory in above-ground biomass when colonized by AMF. This study strongly suggests that AMF positively affect plant tolerance to herbivory in some, but not all, prairie plant species, and that AMF-mediated tolerance is also dependent on the severity of damage. By contrast, mycorrhizal strawberry plants (Fragaria $\times$ ananassa) do not exhibit higher tolerance to herbivory than nonmycorrhizal plants when challenged with the spittlebug pest Philaenus spumarius (Borowicz, 2009). However, even under herbivory, mycorrhizal strawberry plants grow much larger and produce more flowers and runners than do nonmycorrhizal plants. The results of these studies suggest that AMF can mediate increases in plant tolerance to herbivory, although additional work is required in this area before generalizations can be made.

We should also note that almost all studies manipulating the presence of $\mathrm{AMF}$ and examining herbivore responses have used 
fungal species or isolates within the genus Glomus. Although agricultural AMF communities are heavily dominated by members of the Glomaceae (Toljander et al., 2008), AMF species from other genera with different life-history and allocation strategies (Hart \& Reader, 2002) are frequently found in production systems and may elicit different responses in host plants and their insect herbivores.

\section{Conclusions and future directions}

Our review of the literature leads us to draw a number of conclusions and to suggest some strategies for future research. First, in organic and traditional low-input agricultural systems, AMF are likely to increase the nutritional status of plants, with two potentially opposing effects. On the negative side, insects that are limited by phosphorus and/or nitrogen will probably be attracted to, and perform better upon, AMF crops. On the positive side, AMF crops will probably be much more tolerant to insect damage and may have the nutrient resources available to pay the enzymatic costs of defence production. Second, irrespective of fertilizer inputs, AMF may increase the induction of JA-mediated defences and decrease the time required to induce them (so-called 'priming'). Induction of direct and indirect defences, and subsequent attack by parasitoids, should negatively affect most insect herbivores. Finally, those phloem-feeding insects that can avoid the induction of JA-associated defences may be more likely to reap the benefits of AMF on plant nutrition without suffering the costs of higher defence.

Overall, we were struck by the need for both fundamental and applied research on interactions between AMF, crop defence and insect damage. We suggest that the areas discussed below should be targeted for future work.

\section{The influence of AMF on plant tolerance to herbivores}

The manipulation of mycorrhizal fungi to increase crop tolerance to pest attack appears to be an overlooked application of AMF in crop protection. By providing nutrients and water essential for re-growth after damage, we might expect AMF to help maintain crop yields in the face of insect attack. Potential effects are easily illustrated on traditional damage-yield curves (Fig. 1) (Pedigo et al., 1986), which can inform management decisions through the determination of Economic Injury Levels (EILs).

Agricultural crops vary in the levels of pest damage that they can sustain before yields decline and economic losses ensue (Fig. 1). We hypothesize that AMF alter the effects of pest damage on crop yields, depending on the type of agricultural system or, more specifically, based on the relative costs and benefits of hosting AMF. In heavily-managed systems, the cost of maintaining mycorrhizal fungi may outweigh the potential benefits to tolerance, and overall crop yields may decrease for a given level of pest damage (Fig. 2b). Note that such effects on yield per unit damage are beyond any effects that AMF may have on increased crop resistance (lower pest densities) in highly-managed systems. In low-input systems, AMF may

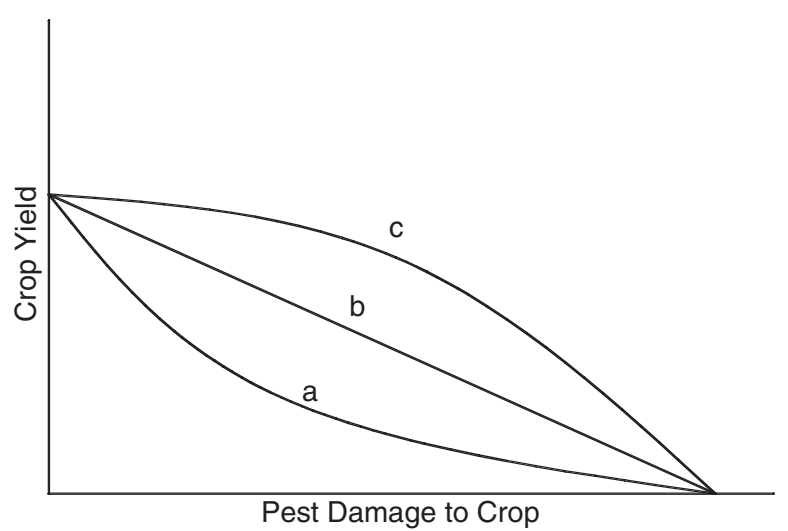

Figure 1 Traditional damage-yield curves illustrating the effects of pest damage on crop yield of (a) intolerant plants, (b) moderately tolerant plants and (c) highly tolerant plants.

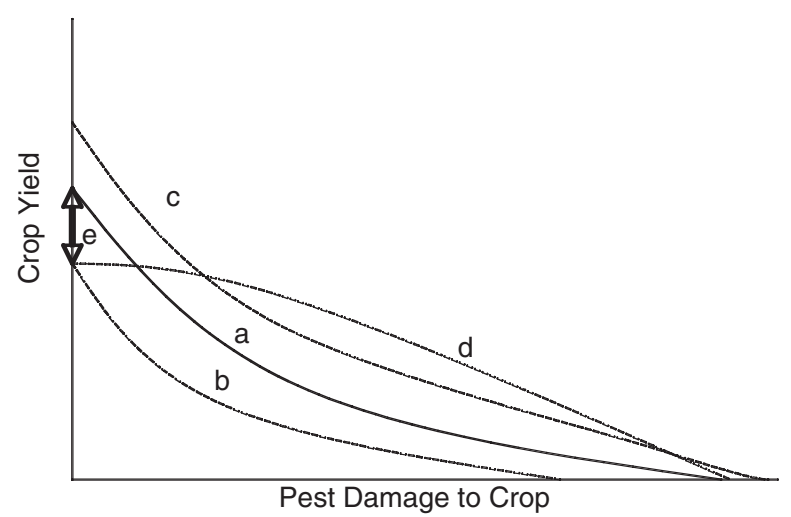

Figure 2 Hypothetical damage-yield curves illustrating potential effects of arbuscular mycorrhizal fungi (AMF) on the yield of pest-intolerant crops after damage. Lines depict (a) nonmycorrhizal control, (b) a mycorrhizal crop in a highly-fertilized and irrigated system where costs of hosting AMF outweigh benefits to tolerance, (c) a mycorrhizal crop in a low-input agricultural system where AMF may increase overall yield and (d) a mycorrhizal crop where AMF increases tolerance to pest damage, such that crop yield declines more slowly as pest damage increases. The distance (e) on the $y$-intercept represents the yield cost of AMF-induced tolerance, expressed when herbivores are absent.

positively affect plant growth and nutritional status, increasing yields above those of nonmycorrhizal controls. However, tolerance (i.e. the rate of decline in yield with increasing damage) may remain unchanged (Fig. 2c). Alternatively, AMF may increase crop tolerance to pest damage relative to controls by increasing nutrient availability and plant re-growth (Fig. 2d). The difference between crop yields with and without AMF in the absence of herbivore damage represents the yield costs of AMF-induced increases in tolerance (Fig. 2e). Although the present review focuses on insect pest damage, plant responses to fungal pathogens may be similarly affected by AMF. We suggest that defining the shapes of AMF-induced damage-yield curves is a priority area for future research, recognizing that the identity and abundance of mycorrhizal fungi will affect nutrient transfer, costs and benefits to plants (Gange \& Ayres, 1999; 
Hart \& Reader, 2002) and the shapes of damage-yield curves (Bennett \& Bever, 2007).

\section{The effects of AMF identity on resistance and tolerance to herbivores}

We have noted that most studies of $\mathrm{AMF}$-insect interactions have been restricted to AMF in the genus Glomus. AMF exhibit different life-history and allocation strategies (Hart \& Reader, 2002) that are likely to influence plant defence and insect responses. For example, the AMF species Archaeospora trappei increases $P$. lanceolata tolerance to herbivory, whereas Glomus 'white' and Scutellospora calospora do not promote tolerance (Bennett \& Bever, 2007). Different strains of AMF also elicit different molecular responses in their host plants (Feddermann et al., 2008). Given that molecular work clearly ties AMF colonization to increases in JA levels, future studies should test explicitly the proposed link between mycorrhizal effects on induced defences and changes in herbivore performance. In time, it may be possible to select specific fungal strains to induce defence pathways in crops that are most appropriate to the pests of greatest concern. The bottom line is that there exists a critical need for more studies that examine the influence of AMF identity on plant-insect interactions (Wooley \& Paine, 2007).

\section{The effects of AMF abundance on resistance and tolerance to herbivores}

All mutualisms are subject to inherent nonlinearities because of density-mediated changes in the net costs and benefits of mutualism (Hernandez, 1998; Bronstein, 2001). We might therefore expect to observe substantial variation in the effects of AMF on crop defence based upon the density of partners, the identity of partners and the availability of resources in the environment (Johnson et al., 1997). In agricultural systems, managers may have to augment fields with AMF in areas where fungal inoculum is limiting (Lekberg \& Koide, 2005). However, over-inoculating may result in growth depressions and decreased defences if fungi become a carbon drain (Laird \& Addicott, 2007). Research on how the availability of AMF inoculum influences crop yield under insect attack is sorely needed.

\section{The effects of AMF on attraction and performance of natural enemies}

There are some intriguing hints that AMF may influence VOC production in plants (Gange et al., 2003; Rapparini et al., 2008), with the potential to influence predator and parasitoid attack of insect pests. Biological control remains a key component of integrated pest management, and is playing an increasing role in organic and conservation agriculture (Speight $e t$ al ., 2008). We require a concerted effort to understand the potential impacts of AMF on VOC production, the subsequent effects on enemy attraction and performance and, ultimately, the levels of insect damage to crop plants that result.

\section{Acknowledgements}

We acknowledge funding from the National Science Foundation (DEB 0814340) to M.D.H. and R.L.V. and additional support from the University of Michigan Department of Ecology and Evolutionary Biology to R.L.V.

\section{References}

Abu-Zeyad, R, Khan, A.G. \& Khoo, C. (1999) Occurrence of arbuscular mycorrhiza in Castanospermum australe A. Cunn. \& C. Fraser and effects on growth and production of castanospermine. Mycorrhiza, 9, 111-117.

Agrawal, A.A. \& Fishbein, M. (2006) Plant defense syndromes. Ecology, 87, S132-S149.

Alguacil, M.M., Lumini, E., Roldan, A., Salinas-Garcia, J.R., Bonfante, P. \& Bianciotto, V. (2008) The impact of tillage practices on arbuscular mycorrhizal fungal diversity in subtropical crops. Ecological Applications, 18, 527-536.

Bennett, A.E. \& Bever, J.D. (2007) Mycorrhizal species differentially alter plant growth and response to herbivory. Ecology, 88, 210-218.

Bennett, A.E., Alers-Garcia, J. \& Bever, J.D. (2006) Three-way interactions among mutualistic mycorrhizal fungi, plants, and plant enemies: Hypotheses and synthesis. American Naturalist, 167, 141-152.

Bezemer, T.M. \& van Dam, N.M. (2005) Linking aboveground and belowground interactions via induced plant defenses. Trends in Ecology and Evolution, 20, 617-624.

Borowicz, V.A. (1997) A fungal root symbiont modifies plant resistance to an insect herbivore. Oecologia, 112, 534-542.

Borowicz, V.A. (2009) Organic farm soil improves strawberry growth but does not diminish spittlebug damage. Journal of Sustainable Agriculture, 33, 177-188.

Bronstein, J.L. (2001) The exploitation of mutualisms. Ecology Letters, 4, 277-287.

Bryant, J.P., Chapin, F.S. \& Klein, D.R. (1983) Carbon nutrient balance of boreal plants in relation to vertebrate herbivory. Oikos, 40, $357-368$

Coleman, D.C., Crossley, D.A. \& Hendrix, P.F. (2004) Fundamentals of Soil Ecology (ed. by D.C. Coleman, D.A. Crossley, Jr. \& P.F. Hendrix). Elsevier Academic Press, The Netherlands.

Conrath, U., Beckers, G.J.M., Flors, V. et al. (2006) Priming: getting ready for battle. Molecular Plant-Microbe Interactions, 19, 1062 1071.

Crush, J.R. (1974) Plant-growth responses to vesicular-arbuscular mycorrhizae. 7. Growth and nodulation of some herbage legumes. New Phytologist, 73, 743-747.

De Moraes, C.M., Lewis, W.J., Pare, P.W., Alborn, H.T. \& Tumlinson, J.H. (1998) Herbivore-infested plants selectively attract parasitoids. Nature, 393, 570-573.

Denno, R.F. \& Fagan, W.F. (2003) Might nitrogen limitation promote omnivory among carnivorous arthropods?. Ecology, 84, 2522-2531.

Devoto, A. \& Turner, J.G. (2005) Jasmonate-regulated Arabidopsis stress signalling network. Physiologia Plantarum, 123, 161-172.

Egerton-Warburton, L.M., Johnson, N.C. \& Allen, E.B. (2007) Mycorrhizal community dynamics following nitrogen fertilization: a crosssite test in five grasslands. Ecological Monographs, 77, 527-544.

Elser, J.J., Sterner, R.W., Gorokhova, E. et al. (2000) Biological stoichiometry from genes to ecosystems. Ecology Letters, 3, 540-550.

Feddermann, N., Boller, T., Salzer, P., Elfstrand, S., Wiemken, A. \& Elfstrand, M. (2008) Medicago truncatula shows distinct patterns of mycorrhiza-related gene expression after inoculation with three different arbuscular mycorrhizal fungi. Planta, 227, 671-680.

Gange, A.C. (2001) Species-specific responses of a root-and shootfeeding insect to arbuscular mycorrhizal colonization of its host plant. New Phytologist, 150, 611-618. 
Gange, A.C. \& Ayres, R.L. (1999) On the relation between arbuscular mycorrhizal colonization and plant 'benefit'. Oikos, 87, 615-621.

Gange, A.C. \& West, H.M. (1994) Interactions between arbuscular mycorrhizal fungi and foliar-feeding insects in plantago-lanceolata L. New Phytologist, 128, 79-87.

Gange, A.C., Stagg, P.G. \& Ward, L.K. (2002) Arbuscular mycorrhizal fungi affect phytophagous insect specialism. Ecology Letters, 5, 1115.

Gange, A.C., Brown, V.K. \& Aplin, D.M. (2003) Multitrophic links between arbuscular mycorrhizal fungi and insect parasitoids. Ecology Letters, 6, 1051-1055.

Gershenzon, J. (1994) Metabolic costs of terpenoid accumulation in higher-plants. Journal of Chemical Ecology, 20, 1281-1328.

Goverde, M., van der Heijden, M.G.A., Wiemken, A., Sanders, I.R. \& Erhardt, A. (2000) Arbuscular mycorrhizal fungi influence life history traits of a lepidopteran herbivore. Oecologia, 125, 362-369.

Guerrieri, E., Lingua, G., Digilio, M.C., Massa, N. \& Berta, G. (2004) Do interactions between plant roots and the rhizosphere affect parasitoid behaviour? Ecological Entomology, 29, 753-756.

Hamilton, J.G., Zangerl, A.R., DeLucia, E.H. \& Berenbaum, M.R. (2001) The carbon-nutrient balance hypothesis: its rise and fall. Ecology Letters, 4, 86-95.

Hart, M.M. \& Reader, R.J. (2002) Host plant benefit from association with arbuscular mycorrhizal fungi: variation due to differences in size of mycelium. Biology and Fertility of Soils, 36, 357-366.

Hause, B., Maier, W., Miersch, O., Kramell, R. \& Strack, D. (2002) Induction of jasmonate biosynthesis in arbuscular mycorrhizal barley roots. Plant Physiology, 130, 1213-1220.

Hause, B., Mrosk, C., Isayenkov, S. \& Strack, D. (2007) Jasmonates in arbuscular mycorrhizal interactions. Phytochemistry, 68, 101-110.

Heidel, A.J. \& Baldwin, I.T. (2004) Microarray analysis of salicylic acid- and jasmonic acid-signalling in responses of Nicotiana attenuata to attack by insects from multiple feeding guilds. Plant Cell and Environment, 27, 1362-1373.

Herms, D.A. \& Mattson, W.J. (1992) The dilemma of plants-to grow or defend. Quarterly Review of Biology, 67, 283-335.

Hernandez, M.J. (1998) Dynamics of transitions between population interactions: a nonlinear interaction alpha-function defined. Proceedings of the Royal Society of London Series B, Biological Sciences, 265, 1433-1440.

Hooper, D.U., Bignell, D.E., Brown, V.K. et al. (2000) Interactions between aboveground and belowground biodiversity in terrestrial ecosystems: patterns, mechanisms, and feedback. BioScience, 50, 1049-1061.

Hunter, M.D. (2000) Mixed signals and cross-talk: Interactions between plants, insect herbivores, and plant pathogens. Agricultural and Forest Entomology, 2, 155-160.

Hunter, M.D. (2002) A breath of fresh air: beyond laboratory studies of plant volatile-natural enemy interactions. Agricultural and Forest Entomology, 4, 81-86.

Hunter, M.D. (2003) Effects of plant quality on the population ecology of parasitoids. Agricultural and Forest Entomology, 5, 1-8.

Janos, D.P. (2007) Plant responsiveness to mycorrhizas differs from dependence upon mycorrhizas. Mycorrhiza, 17, 75-91.

Johnson, N.C. (1993) Can fertilization of soil select less mutualistic mycorrhizae? Ecological Applications, 3, 749-757.

Johnson, N.C., Graham, J.H. \& Smith, F.A. (1997) Functioning of mycorrhizal associations along the mutualism-parasitism continuum. New Phytologist, 135, 575-586.

Karban R. and Baldwin I.T. (1997) Induced Responses to Herbivory. University of Chicago Press, Chicago, Illinois.

Kula, A.A.R., Hartnett, D.C. \& Wilson, G.W.T. (2005) Effects of mycorrhizal symbiosis on tallgrass prairie plant-herbivore interactions. Ecology Letters, 8, 61-69.
Laird, R.A. \& Addicott, J.F. (2007) Arbuscular mycorrhizal fungi reduce the construction of extrafloral nectaries in Vicia faba. Oecologia, 152, 541-551.

Lekberg, Y. \& Koide, R.T. (2005) Is plant performance limited by abundance of arbuscular mycorrhizal fungi? A meta-analysis of studies published between 1988 and 2003. New Phytologist, 168, 189-204.

Lekberg, Y., Koide, R.T. \& Twomlow, S.J. (2008) Effect of agricultural management practices on arbuscular mycorrhizal fungal abundance in low-input cropping systems of southern Africa: a case study from Zimbabwe. Biology and Fertility of Soils, 44, 917-923.

Liu, J.Y., Maldonado-Mendoza, I., Lopez-Meyer, M., Cheung, F., Town, C.D. \& Harrison, M.J. (2007) Arbuscular mycorrhizal symbiosis is accompanied by local and systemic alterations in gene expression and an increase in disease resistance in the shoots. Plant Journal, 50, 529-544.

van Loon, L.C., Bakker, P. \& Pieterse, C.M.J. (1998) Systemic resistance induced by rhizosphere bacteria. Annual Review of Phytopathology, 36, 453-483.

Lorenzo, O. \& Solano, R. (2005) Molecular players regulating the jasmonate signalling network. Current Opinion in Plant Biology, 8 , $532-540$.

Meixner, C., Ludwig-Muller, J., Miersch, O., Gresshoff, P., Staehelin, C. \& Vierheilig, H. (2005) Lack of mycorrhizal autoregulation and phytohormonal changes in the supernodulating soybean mutant nts1007. Planta, 222, 709-715.

Miller, R.M., Miller, S.P., Jastrow, J.D. \& Rivetta, C.B. (2002) Mycorrhizal mediated feedbacks influence net carbon gain and nutrient uptake in Andropogon gerardii. New Phytologist, 155, 149-162.

Pedigo, L.P., Hutchins, S.H. \& Higley, L.G. (1986) Economic injury levels in theory and practice. Annual Review of Entomology, 31, 341-368.

Piotrowski, J.S. \& Rillig, M.C. (2008) Succession of arbuscular mycorrhizal fungi: patterns, causes, and considerations for organic agriculture. Advances in Agronomy, Vol 97, pp. 111-130. Elsevier Academic Press Inc., San Diego, California.

Rapparini, F., Llusia, J. \& Penuelas, J. (2008) Effect of arbuscular mycorrhizal (AM) colonization on terpene emission and content of Artemisia annua L. Plant Biology, 10, 108-122.

Redecker, D., Kodner, R. \& Graham, L.E. (2000) Glomalean fungi from the Ordovician. Science, 289, 1920-1921.

Rosenthal, J.P. \& Kotanen, P.M. (1994) Terrestrial plant tolerance to herbivory. Trends in Ecology and Evolution, 9, 145-148.

Smith, S.E. \& Read, D.R. (2008) Mycorrhizal Symbiosis, 3rd edn. Academic Press, New York, New York.

Speight, M.R., Hunter, M.D. \& Watt, A.D. (2008) Ecology of Insects: Concepts and Applications, 2nd edn. Wiley-Blackwell, Hoboken, New Jersey.

Stowe, K.A. (1998) Experimental evolution of resistance in Brassica rapa: correlated response of tolerance in lines selected for glucosinolate content. Evolution, 52, 703-712.

Subhashini, D.V. \& Krishnamurty, V. (1995) Influence of vesiculararbuscular mycorrhiza on phosphorus economy, yield and quality of flue-cured Virginia tobacco in rain-fed Alfisols. Mycorrhizae: biofertilizers for the future. Proceedings of the Third National Conference on Mycorrhiza; 1995 March 13-15 (ed. by A. Adholeya \& S. Singh), pp. 328-330. Tata Energy Research Institute, New Delhi.

Tawaraya, K. (2003) Arbuscular mycorrhizal dependency of different plant species and cultivars. Soil Science and Plant Nutrition, 49, 655-668.

Toljander, J.F., Santos-Gonzalez, J.C., Tehler, A. \& Finlay, R.D. (2008) Community analysis of arbuscular mycorrhizal fungi and bacteria in the maize mycorrhizosphere in a long-term fertilization trial. Fems Microbiology Ecology, 65, 323-338. 
Treseder, K.K. (2004) A meta-analysis of mycorrhizal responses to nitrogen, phosphorus, and atmospheric $\mathrm{CO}_{2}$ in field studies. New Phytologist, 164, 347-355.

Vallad, G.E. \& Goodman, R.M. (2004) Systemic acquired resistance and induced systemic resistance in conventional agriculture. Crop Science, 44, 1920-1934.

Van der Meijden, E., Wijn, M. \& Verkaar, H.J. (1988) Defence and regrowth, alternative plant strategies in the struggle against herbivores. Oikos, 51, 355-363.

Van Wees, S.C.M., Van der Ent, S. \& Pieterse, C.M.J. (2008) Plant immune responses triggered by beneficial microbes. Current Opinion in Plant Biology, 11, 443-448.

Wang, B. \& Qiu, Y.L. (2006) Phylogenetic distribution and evolution of mycorrhizas in land plants. Mycorrhiza, 16, 299-363.
Wardle, D.A., Bardgett, R.D., Klironomos, J.N., Setala, H., van der Putten, W.H. \& Wall, D.H. (2004) Ecological linkages between aboveground and belowground biota. Science, 304, 1629-1633.

Woods, H.A., Fagan, W.F., Elser, J.J. \& Harrison, J.F. (2004) Allometric and phylogenetic variation in insect phosphorus content. Functional Ecology, 18, 103-109.

Wooley, S. \& Paine, T. (2007) Can intra-specific genetic variation in arbuscular mycorrhizal fungi (Glomus etunicatum) affect a mesophyll-feeding herbivore (Tupiocoris notatus Distant)? Ecological Entomology, 10, 1365-2311.

Accepted 6 January 2009 